\title{
Estimating the Potential Output and Output Gap of Ghana
}

\author{
Joseph Atta-Mensah $^{1} \&$ Sawuya Nakijoba ${ }^{1}$ \\ ${ }^{1}$ Capacity Development Division, United Nations Economic Commission for Africa, Addis Ababa, Ethiopia \\ Correspondence: Joseph Atta-Mensah, Capacity Development Division, United Nations Economic Commission for \\ Africa, Addis Ababa, Ethiopia. (All correspondence should be directed to the first Author, Joseph Atta-Mensah.)
}

Received: February 22, 2019

Accepted: March 21, $2019 \quad$ Available online: April 11, 2019

doi:10.11114/aef.v6i3.3958

URL: https://doi.org/10.11114/aef.v6i3.3958

\begin{abstract}
This paper focuses on the estimation of the potential output of Ghana. Potential output or its derivative the output gap are not observable. However, "potential output" is a powerful conceptual tool that guides analysts and policymakers in gauging whether the current observed economic activity is sustainable and how much of it is greater than or less than potential. Based on Ghanaian GDP annual data from 1960 - 2017, the paper estimates potential output and output gaps using the following methodology: linear time trends, Hodrick-Prescott (HP) filter trends, multivariate HP filter trends, and a production function model. The results show that estimates of the potential output and output gaps are modeldependent as estimates vary from one methodology to the other. The paper recommends that policymakers should not mechanically choose a model to estimate output gap. For the avoidance of costly policy mistakes, the choice of the model should be complemented with sound judgement based on a set of pertinent economic information.
\end{abstract}

Keywords: potential output, output gap, hodrick-prescott (HP) filter trends, multivariate HP, a production function model JEL Clasificacion: E23, E24, E31, E32, E37 and E39

\section{Introduction}

Managers of a country's economy, particularly those in the central banks, pay significant attention to the movements of potential output. A good understanding of potential output is needed to guide policymakers on how to calibrate the effective size of the fiscal and monetary policies that the economy would need. Policy makers therefore constantly estimate the output gap, or the difference between real output and potential output. In the economic literature potential output is defined as the real output achieved when an economy uses a high rate of its resources for production.

The output gap, which is the difference between actual output and potential output, is an important indicator for policymakers and therefore it is key that the potential is estimated with minimum errors. A wrong estimate of the potential output and consequently the output gap will result in policy errors. For example, if the true measure of the potential output is large, but estimated wrongly to be smaller then a policymaker will estimate the output gap to be negative or in other words current output is assumed to be performing below its potential. Consequently, actions taken by policymakers will impact negatively as resources and capacity will be underutilized. This means that the estimation of the potential output is very critical to the conduct of effective macroeconomic policies.

The direction of intervening macroeconomic policies is determined by the output gap determines. Managers of the economy are expected to pursue either expansionary fiscal or monetary policy or a combination of both when the output gap is positive. On the other hand, when the output gap is negative policymakers embark on contractionary monetary or fiscal policy or a combination of both so as to reduce aggregate demand. The output gap therefore plays an important role in the setting of interest rate by central banks. Some central bankers set interest rate based on a rule of thumb called the Taylor rule, which is a weighted sum of the difference between the actual and targeted inflation rate and the output gap.

The paper is organized as follows. Section 2 provides a discussion on the various methods of estimating potential output. Section 3 deals with the data and analysis of the results carried out in the paper. Concluding remarks are made in Section 4. 


\section{Methods of Estimating Potential Output}

Okun (1962) defines potential output as the non-inflationary level of output. However, the estimation of potential output is very difficult as it is not observable. ${ }^{1}$ Hence there is no agreed method of estimation among economists and researchers. There are therefore different methodologies for estimating potential output. Each method has its strengths and weakness. The methodologies found in the literature for estimating potential output can be grouped into two categories: the production function approach and the statistical approach. The first approach is based on the definition of output as a function of capital and labour and therefore potential output is achieved when labour and capital are fully utilized. General approach to the estimation by the production function is to postulate the Cobb-Douglas production function with constant returns to scale.

The second approach to estimating potential output uses statistical methods, based on reliable and readily available data. These statistical methods involve decomposing actual real GDP into two components, a trend and a cyclical component, with the trend representing potential output. The use of the statistical method assumes that GDP growth rate is driven by an underlying structural component (trend) and a random component (cyclical). The random component could be caused by factors including natural variations in the business cycles, external demand and supply shocks. In applying the statistical method, the estimate of potential output is the derivative (or trend) after the removal of the cyclical component of actual GDP.

\subsection{Linear Model}

Potential output can be estimated from a linear regression of real GDP against a constant and a time trend:

$$
y_{t}=\beta_{0}+\beta_{1} T+\varepsilon_{t}
$$

where $y_{t}$ is natural logarithm of real GDP, $\beta_{0}$ and $\beta_{0}$ are coefficients, T is the time trend and $\varepsilon_{t}$ is the error term. In equation (1) growth of real GDP is determined by the trend component $\left(\beta_{1}\right)$ and the cyclical component $\left(\varepsilon_{t}\right)$. The cyclical component is interpreted by policymakers as the output gap, which, when positive (economy operates above its capacity) indicates excess demand and when negative indicates excess supply (slack). The output gap has empirically been observed to have a strong relationship with price and wage inflation. ${ }^{2}$

A weakness of the linear model for estimating potential output, and consequently the output gap, is that the estimation depends on the sample period. As observed by de Brouwer (1998), the estimation of the output gap from a linear model is very sensitive to the selection of the starting and end-points. The model is also weakened by the assumption that potential output grows at a constant rate. Theoretically, the growth of output is made of growth of labour productivity and labour inputs. Labour inputs are also influenced by the average number of hours worked, labour force participation and changes in population. Given that these are not constant over time, as they change with structural shocks to the economy, potential output can only grow at a time-varying growth rate and therefore not at a constant rate. In general output tends to follow a stochastic trend as it is integrated of order one and therefore non-stationary. Hence the residual derived from a linear trend remains non-stationary and therefore the output gap is not mean-reverting and exhibits persistence to shocks. ${ }^{3}$

\subsection{Hodrick-Prescott Model}

One of the common techniques of estimating potential output is by the model of Hodrick and Prescott (1997) (HP) model or filter because of its simplicity, transparency and applicability. Potential output is estimated by the HP filter is done by minimizing a loss function of the form:

$$
L=\sum_{t=1}^{S}\left(y_{t}-y_{t}^{p}\right)^{2}+\lambda \sum_{t=2}^{S-1}\left(\Delta y_{t+1}^{p}-\Delta y_{t}^{p}\right)^{2}
$$

where $\lambda$ is a smoothing-weight on the growth of potential output, which is responsive to movements in actual output. $S$ is the sample size. The properties of $\lambda$ are such that as it approaches infinity, the loss function is minimised by penalising changes in potential growth. On the other hand, $\lambda$ approaches zero, the loss function is minimised by setting potential output and actual output to be the same.

1 See Alberoa, Estrada, and Santabarbara (2013), Borio, Disyatat, and Juselius (2013) and others for discussions on the estimation of potential output.

2 See Phillips (1958) de Brouwer and Ericsson 1995, Cockerell and Russell 1995, de Brouwer and O'Regan 1997, Debelle and Vickery 1997 for studies on the relationship between the output gap and inflation.

3 See Diebold and Senhadji (1996) for further discussions on this subject. 
A strength of the HP filter is that the output gap is stationary over a wide range of smoothing values (de Brouwer (1998)). A disadvantage is that the estimate of potential output is dependent on the value and consequently the peaks and troughs could be missed. Hodrick and Prescott (1997) suggest that one set $\lambda=100,1600$ and 14400 for annual, quarterly and monthly data respectively as the level of $\lambda$ depends on the relative size of the variances of the shocks to permanent and transitory components to output. ${ }^{4}$

\subsection{Production Function Method}

Another method currently being used by some central banks is the one based on the production function. This method combines factor inputs such as capital and labour in a production function to determine the level of potential output. ${ }^{5}$ The estimation of the potential output based on this approach requires the availability of data on labour, machinery, natural resources and intermediate inputs across diverse sectors of the economy. Furthermore, policymaker would need to choose a formulation for the production function which adequately captures technological progress.

The use of the production function approach implies that output is determined by capital inputs (capital stock and capacity utilisation), labour inputs (hours worked per person and the labour force) and total factor productivity (TFP) as a residual. Trends are extracted from the input series to remove the cyclical and higher frequency components, and those trends are then combined with the production function as potential output. This approach is richer because it focusses on factors that theoretically explain potential output and therefore uses more data than the HP filter.

The production function is:

$$
Y_{t}=A_{t}\left(C_{t} K_{t}\right)^{(1-\alpha)}\left(H_{t} L_{t}\right)^{\alpha}
$$

where $Y_{t}$ is output, $A_{t}$ is TFP, $C_{t}$ is capacity utilisation, $K_{t}$ is capital stock, $H_{t}$ is hours worked per person, and $L_{t}$ is number of persons employed. The parameter $\alpha$ is labour's share in output with $0<\alpha<1$.

The number of persons employed, $L_{t}$, is:

$$
L_{t}=E_{t} P_{t} N_{t}
$$

where $E_{t}$ is the employment rate (hence 1 minus the unemployment rate), $P_{t}$ the participation rate, and $N_{t}$ is the working age population of the economy.

Expressing the production function in logarithmic form yields:

$$
y_{t}=a_{t}+(1-\alpha)\left(c_{t}+k_{t}\right)+\alpha\left(h_{t}+l_{t}\right)
$$

where

$$
l_{t}=e_{t}+p_{t}+n_{t}
$$

With the availability of data for most of the variables, the production function (equation (5)) can be used to derive logarithmic value of the TFP $\left(a_{t}\right)$ as a residual:

$$
a_{t}=y_{t}-(1-\alpha)\left(c_{t}+k_{t}\right)-\alpha\left(h_{t}+l_{t}\right)
$$

Lienert and Gillmore (2015) indicate that potential output estimated by the Reserve Bank of New Zealand for New Zealand is based on the production-function (equations (5) and (6)), in which the inputs of production are considered separately. By separately estimating the trend values of the inputs, the potential output is estimated as:

$$
y_{t}^{p}=\overline{a_{t}}+(1-\alpha)\left(\overline{c_{t}}+\overline{k_{t}}\right)+\alpha\left(\overline{h_{t}}+\overline{l_{t}}\right)
$$

where

$$
\overline{l_{t}}=\overline{e_{t}}+\overline{p_{t}}+\overline{n_{t}}
$$

Once the potential output, $\left(y_{t}^{p}\right)$, has been obtained then output gap(ygap) is estimated as:

$$
\operatorname{ygap}_{t}=y_{t}-y_{t}^{p}
$$

It has to be noted that the method of using the production function method to estimate the potential GDP has the benefit of allowing for a more detailed examination of the drivers of potential. However, it suffers from the reliability of data, particularly capital-stock data which is not easy to find. Hence potential output estimated from this method is as good as the filters used to detrend the TFP and employment components.

4 See Guay and St Amant (1996), King and Rebelo (1993) and Harvey and Jaeger (1993) and St Amant and van Norden (1997) on pertinent on the choice of the smoothing parameter.

5 Lienert and Gillmore (2015) indicates that the potential output and the output gap for New Zealand are based on a Cobb-Douglas production function. 


\subsection{Multivariate Filter Model}

Another approach to estimating potential output is the use of multivariate filter techniques. ${ }^{6}$ The Multivariate technique adds economic structure, by including economic relationships such as the capacity utilization (which contains information about the supply side of the economy at the various stages of a business cycle), the Okun's law (linkages between unemployment and growth) and Phillip's curve (linkages between inflation and the output gap). ${ }^{7}$

The Multivariate approach estimates potential output by minimizing an extended HP loss function of the form:

$$
L=\sum_{t=1}^{S}\left(y_{t}-y_{t}^{p}\right)^{2}+\lambda \sum_{t=2}^{S-1}\left(\Delta y_{t+1}^{p}-\Delta y_{t}^{p}\right)^{2}+\sum_{t=1}^{S} \mu_{t} \varepsilon_{\pi, t}^{2}+\sum_{t=1}^{S} \beta_{t} \varepsilon_{u, t}^{2}+\sum_{t=1}^{S} \psi_{t} \varepsilon_{c u, t}^{2}
$$

where $\varepsilon$ is a residual from a regression, $\mathrm{u}$ and $\mathrm{cu}$ indicate respectively equations for a Phillips curve, Okun's Law and capacity utilisation, and are time-varying weights. These residuals are defined as:

$$
\begin{gathered}
\pi_{t}=\pi_{t}^{e}+A(L)\left(y_{t}-y_{t}^{p}\right)+\varepsilon_{\pi, t} \\
u_{t}=\operatorname{nairu}_{t}-B(L)\left(y_{t}-y_{t}^{p}\right)+\varepsilon_{u, t} \\
c u_{t}=c u_{t}^{T}+C(L)\left(y_{t}-y_{t}^{p}\right)+\varepsilon_{c u, t}
\end{gathered}
$$

Equation (12) which describes a Phillips curve indicates that current inflation is based on expected inflation and the output gap. Equation (13), Okun's Law, suggests the current unemployment rate is determined by the level of non-accelerating inflation rate of unemployment (NAIRU) and the output gap. As pointed out by Conway and Hunt (1997) equation (14) indicates that capacity utilization is determined by its trend and output gap. Equation (11) implies that the multivariate filter technique estimates potential output by minimizing a weighted average of the output gap, changes in the rate of potential growth and the residuals from three conditioning structural equations. The Multivariate technique is far superior to that of the HP filter because of the additional structural relationships which contain pertinent economic information. Furthermore, Blagrave et.al. (2015) empirically finds the multivariate approach to be superior to other techniques in estimating potential output and its output gap derivative.

\subsection{Structural Vector Auto-Regression (SVAR) Method}

Dupasquier et al. (1999) propose structural vector auto-regression (SVAR) for the estimation of potential output. The technique borrows from Blanchard and Quah (1989), Shapiro and Watson (1988), and King et al. (1991) by imposing long-run restrictions on output. It follows the multivariate technique of estimating potential output by imposing structural economic equations based on economic theory. One of the characteristics of the SVAR model is that restrictions are not imposed on the short-run dynamics of the permanent component of the output.

Dupasquier et al. model follows Watson (1993) by letting $Z_{t}$ be a $\mathrm{n} \times 1$ stationary vector, which is made up of a $n_{1^{-}}$vector of I(1) variables and a $n_{2}$-vector of stationary $\mathrm{I}(0)$ variables. The model constraints $Z_{t}=\left(\Delta X_{1 t}^{\prime} \Delta X_{2 t}^{\prime}\right)^{\prime}$. Based on Wold decomposition theorem, $Z_{t}$ is expressed in a reduced form as:

$$
Z_{t}=\delta(t)+C(L) \varepsilon_{t}
$$

where $\delta(t)$ is deterministic, $C(L)=\sum_{i=0}^{\infty} C_{i} L^{i}$ is a matrix of polynomial lags, $C_{0}=I_{n}$ is the identity matrix, the vector $\varepsilon_{t}$ is the one-step-ahead forecast errors such that $E\left(\varepsilon_{t}\right)=0$, and $E\left(\varepsilon_{t} \varepsilon_{t}^{\prime}\right)=\Omega$, a positive definite variance-covariance matrix. A determinantal polynomial $|C(L)|$ is assumed to have all its roots on or outside the unit circle, and therefore avoids the non-fundamental representation, implied in the work of Lippi and Reichlin (1994). Decomposing Equation (15) into its long-run and transitory components yields:

$$
Z=\delta(t)+C(1) \varepsilon_{t}+C^{*}(L) \varepsilon_{t}
$$

where $C(1)=\sum_{i=0}^{\infty} C_{i}$ and $C^{*}(1)$. Equation (16) represents multivariate Beveridge-Nelson decomposition. ${ }^{8} C_{1}(1)$ is the long-run multiplier of vector $X_{1}$. If the rank of $C_{1}(1)$ is less than $n_{1}$, there exists at least one linear combination of the elements in $X_{1 t}$ that is $\mathrm{I}(0)$.

Making the assumption of the following structural form by imposing a long run restriction on output:

$$
Z_{t}=\delta(t)+\Gamma(L) \eta_{t}
$$

6 See Laxton and Tetlow (1992), Kuttner (1994), Benes et. al. (2010) and others on the multivariate approach.

7 Laxton and Tetlow (1992), Blagrave, Garcia-Saltos, Laxton, and Zhang (2015), Alichi (2015) and others suggests an approach which extends the HP filter by incorporating economic information.

8 See Evans and Reichlin (1994) and King et al. (1991). 
where $\eta_{t}$ is a n-vector of structural shocks, $E\left(\eta_{t}\right)=0$, and $E\left(\eta_{t} \eta_{t}^{\prime}\right)=I_{n}$. The structural form (equation 15) can be obtained using the following relationships: $\Gamma_{o} \Gamma_{o}^{\prime}=\Omega, \varepsilon_{t}=\Gamma_{0} \eta_{t}$, and $C(L)=\Gamma(L) \Gamma_{0}^{-1}$.

From equations (16) and (17), $C(1) \Omega C(1)^{\prime}$ is the long-run covariance matrix of the reduced form:

$$
C(1) \Omega C(1)^{\prime}=\Gamma(1) \Gamma(1)^{\prime}
$$

With the appropriate number of restrictions, the matrix $\Gamma_{0}$ can be identified as the long-run covariance matrix of the structural form. ${ }^{9}$ Furthermore, let first variable in the vector $Z_{1 t}$ be defined as $\log$ of output then:

$$
\Delta y_{t}=\mu_{t}+\Gamma_{y}^{p}(L) \eta_{t}^{p}+\Gamma_{y}^{c}(L) \eta_{t}^{c}
$$

where $\eta_{t}^{p}$ is the vector of permanent shocks affecting output and $\eta_{t}^{c}$ is the vector containing shocks having only a transitory effect on output. Potential output is estimated from the following relation:

$$
\Delta y_{t}^{p}=\mu_{t}+\Gamma_{y}^{p}(L) \eta_{t}^{p}
$$

Equation (20) implies that "potential output" is, the permanent component of output. The "output gap," which is the transitory component is:

$$
\Delta y_{t}^{c}=\Gamma_{y}^{c}(L) \eta_{t}^{c}
$$

Compared to Blanchard and Quah (1989) which explains the estimation model in terms of "demand" or "supply" shocks, Dupasquier et al prefer to offer a simple explanation in terms of permanent and transitory shocks. This is because a transitory negative output gap could be generated from a positive technological shock whose short-term impact is smaller than its long-term impact. ${ }^{10}$

\section{Data and Analysis of Results}

This study uses annual time series data, from 1960-2017, obtained from World Development Indicators of the World Bank to estimate potential output of Ghana. The study uses GDP at purchaser's prices. ${ }^{11}$

\subsection{Linear Time Trend Method}

A simple method of estimating potential output is the linear time trend. Our estimation of logged annual GDP (y), from 1960 to 2017, gives:

$$
\begin{gathered}
y_{t}=9.9656+0.029 \text { trend } \\
\text { se }(0.141) \quad(0.0042) \\
t \quad(70.614) \quad(6.904)
\end{gathered}
$$

Durbin-Watson stat $=0.0794 ;$ adj $R^{2}=0.988$

The implication of the estimates in equation (22) is that trend growth in output in Ghana, grew around 2.9 percent on average from 1960 to 2017. Figure 1 plots the estimated potential output from the linear trend and the actual output. Figure 2 displays the estimated output gap. As indicated in the earlier section the estimation of the output gap by the linear trend is very sensitive to the sample period as varying the starting points affects the size of the output gap making the estimates of the gap very unstable. A second deficiency of estimating the output gap by the linear trend approach is that its assumption that potential output grows at a constant rate. Economic theory posits that output growth is made up of labour inputs and growth of labour productivity. However, movements in labour force participation, average hours worked and labour productivity and population as a result of economic shocks affect labour productivity. Hence, potential output cannot be assumed to grow at a constant rate. The evolution of the economy as a result of structural changes suggests that the growth of output will be time-varying and therefore not constant.

Following Diebold and Senhadji (1996) and others, we conducted statistical test to assess what trend the Ghanaian GDP followed. Table 1 presents our results for the period 1960 to 2017. Rows 1 and 2 clearly show that the Ghanaian output

9 Blanchard and Quah (1989) and Shapiro and Watson (1988) use long-run restrictions to identify shocks with $C$ (1) having full rank. King et al. (1991) work in a context where the rank of $C(1)$ is less than $n_{1}$ and they use cointegration restrictions.

10 Given that the economy is likely to remain on its production possibility frontier as adjustments unfold, it is recommended that policymaker and researchers include the diffusion process associated with permanent shocks in potential output since. In many models used for policy analysis there will then be no reason for trend inflation to change.

11 GDP at purchaser's prices is defined as the sum of gross value added by all resident producers in the economy plus any product taxes and minus any subsidies not included in the value of the products. It is calculated without making deductions for depreciation of fabricated assets or for depletion and degradation of natural resources. 
follows a stochastic trend while the output gap (rows 3 and 4) is found to be non-stationary, confirming the results of Hodrick and Prescott (1997) that another method of estimating potential output is preferable than the linear trend.

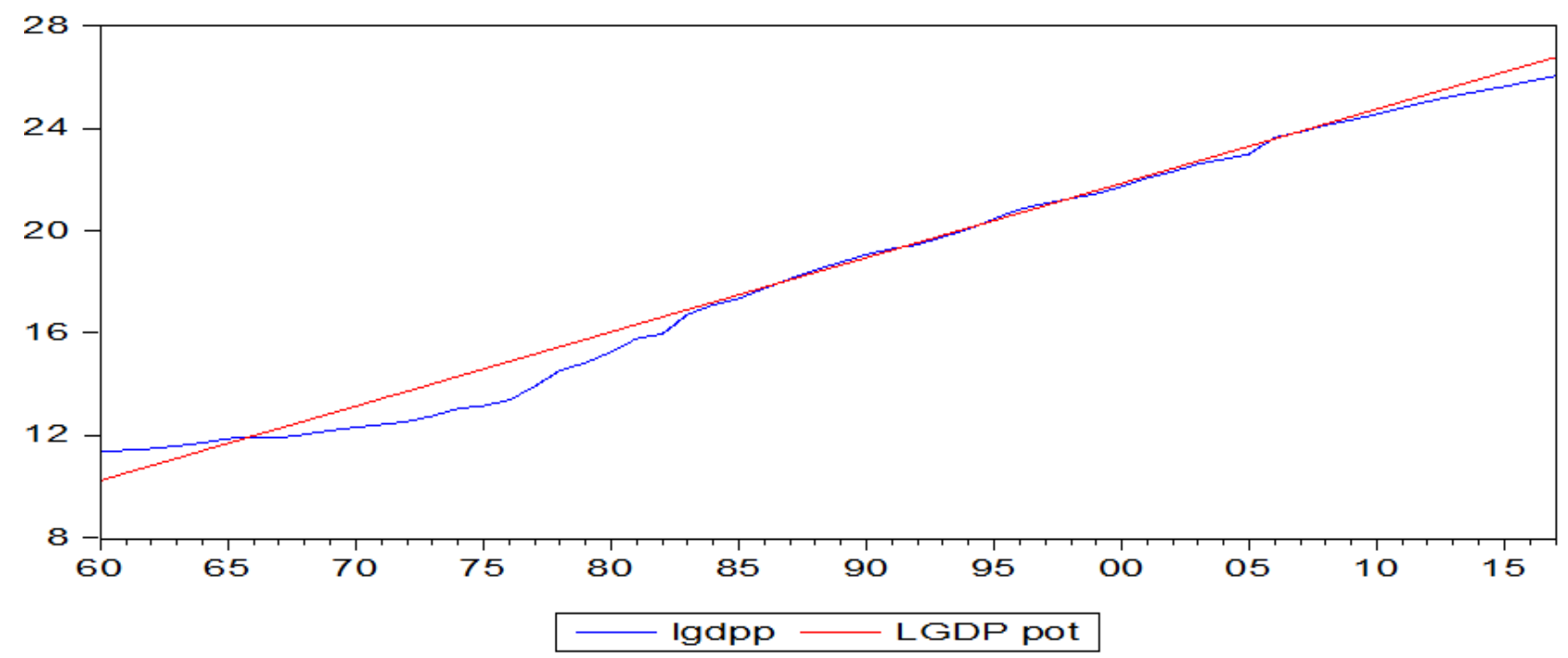

Figure 1. Actual and potential GDP from Linear Trend Model

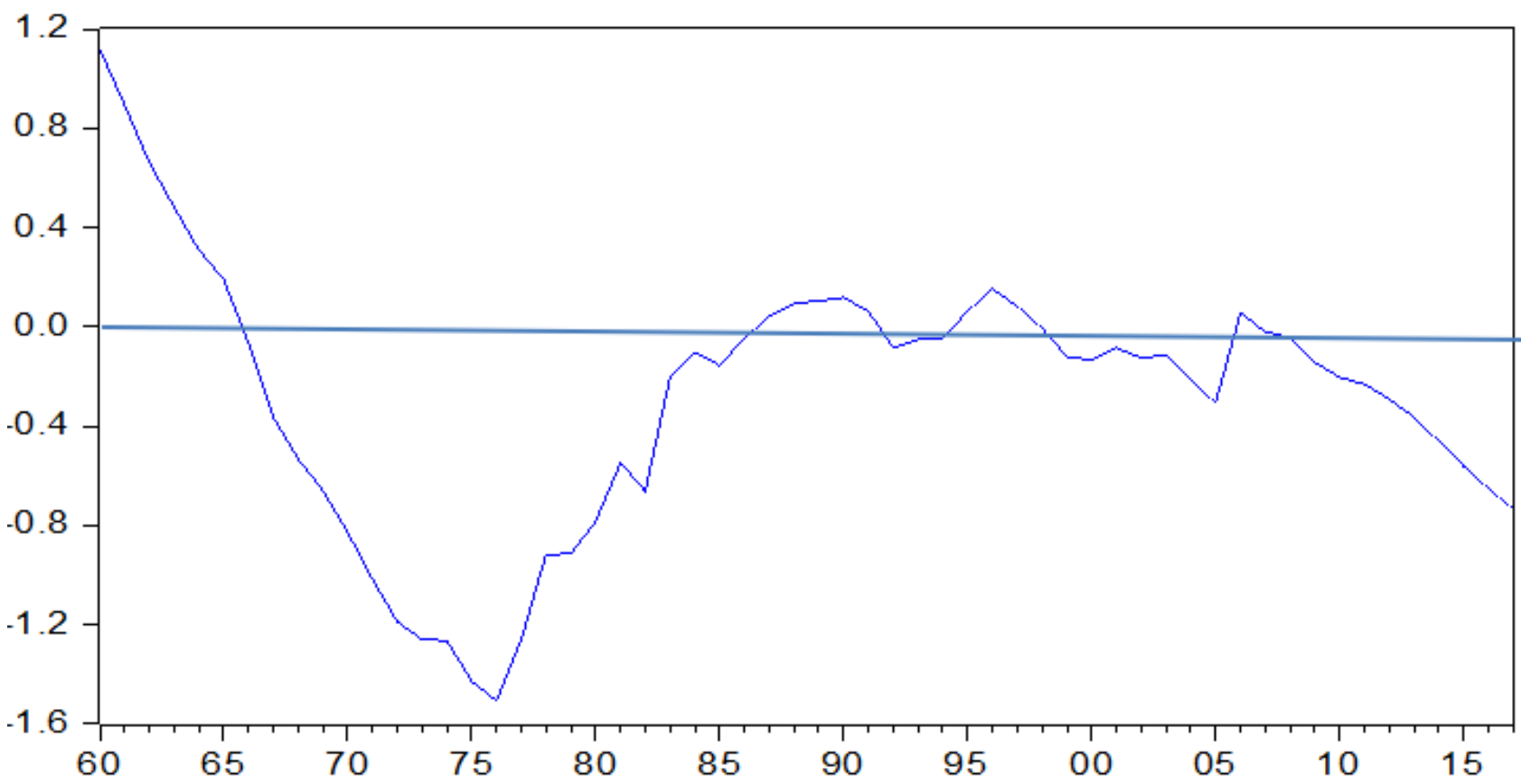

Figure 2. Estimated Output Gap from Linear Trend Model

Table 1. ADF Test for Unit Roots in Output and the Output Gap

H0: series has unit root

\begin{tabular}{llll}
\hline Variable & Constant & Trend & Lag level \\
\hline LGDP & $0.169(2.21)$ & $0.029(2.73)$ & $-0.140(2.32)$ \\
$\Delta$ LDGP & $0.164(0.64)$ & $0.0008(0.67)$ & $-0.64(5.05) * * *$ \\
Linear trend gap & $0.001(1.67)$ & $-0.05(-2.72)$ & $-0.139(2.73)$ \\
$\Delta$ Linear trend gap & $-0.017(-0.91)$ & $-0.0008(-0.67)$ & $-0.62(-5.04) * * *$ \\
\hline
\end{tabular}

$\mathrm{t}$-values are in parentheses with $* * *$ and $* * *$ indicating significant levels at 10,5 and $1 \%$ respective

\subsection{Hodrick-Prescott Filter}

Given the weakness of estimating potential output by the linear model, the paper assessed the performance of using the Hodrick Prescott filter. The advantage of the HP filter is that the growth rate of the estimated potential output is time 
varying while the estimated output gap is stationary. A disadvantage is how the smoothing weight $\lambda$ is set as it is arbitrary. This is because the level of the smoothing parameter affects the size of the estimate of potential output, with the larger size of the parameter yielding a higher level of potential output. The relative scale and timing of peaks and troughs in potential output is also affected by the choice of the smoothing parameter.

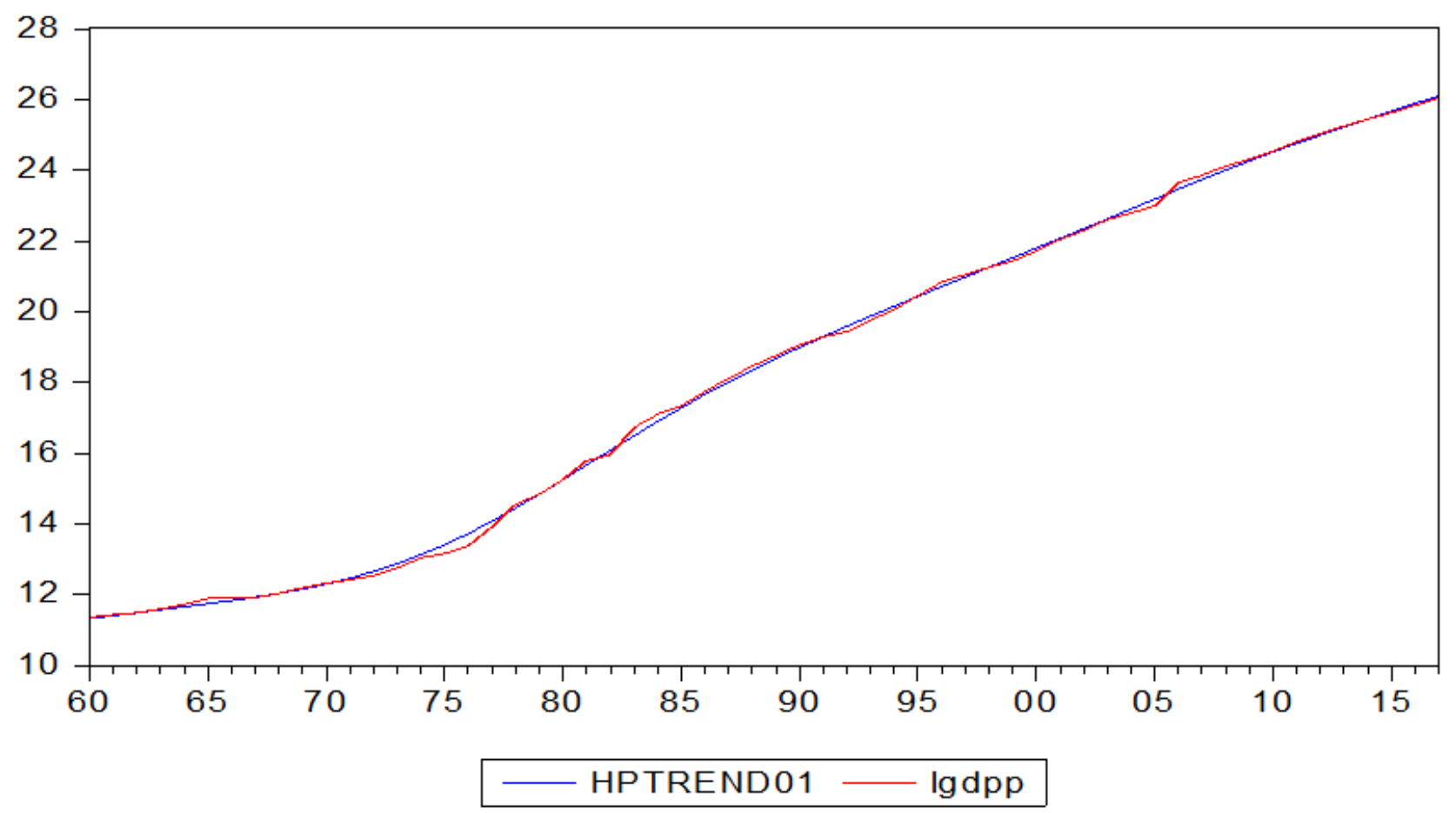

Figure 3. Actual and Trend Output (HP Filter)

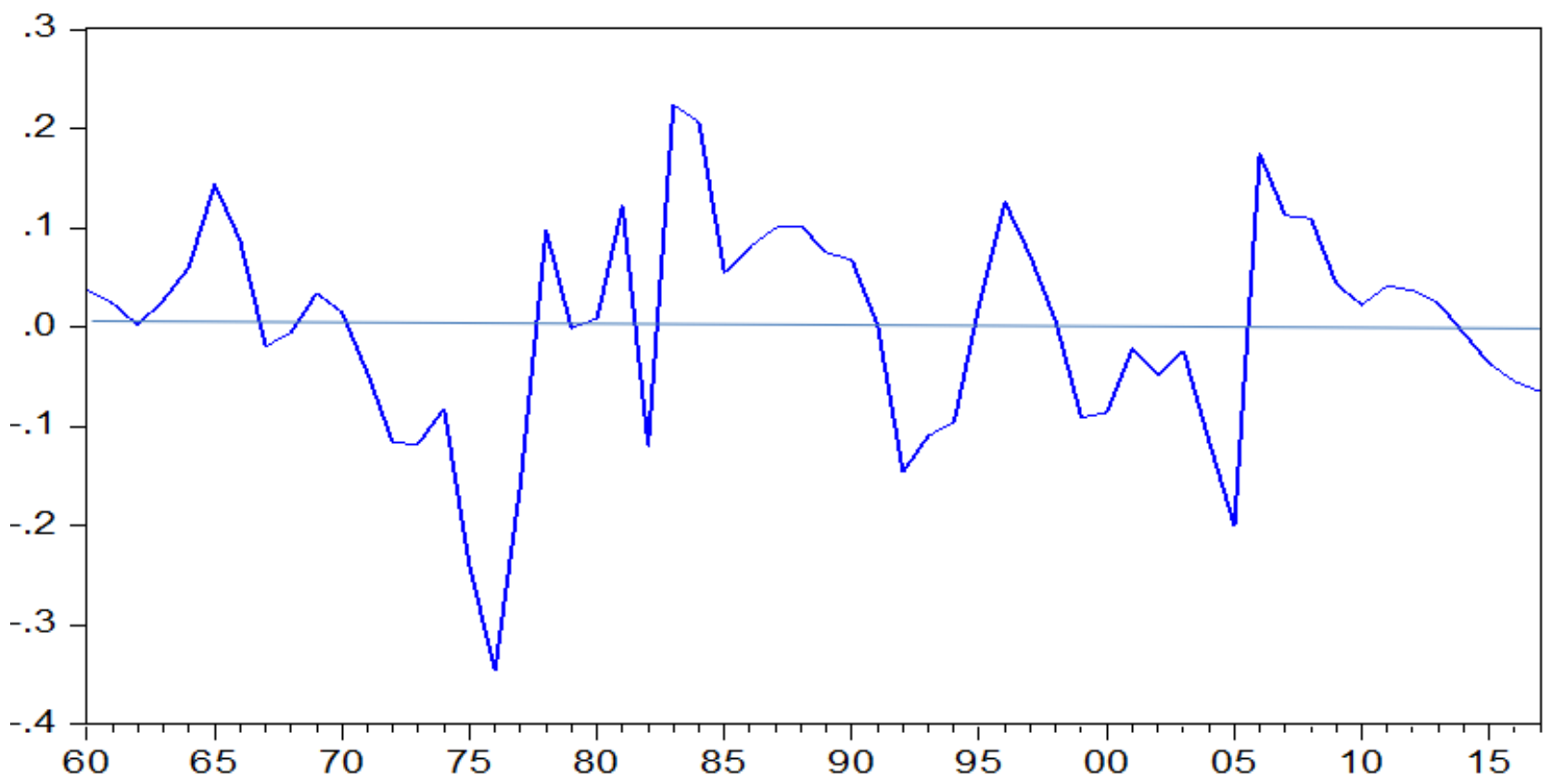

Figure 4. Estimated Output Gap from the HP Filter

Figure 3 displays the estimated potential output from the HP Filter and actual for Ghana from 1960 to 2017 using annual data. Consistent with the empirical work in the literature, the smoothing parameter, is set at 100 as annual data is being used $^{12}$.The derived output gap from the estimated potential is presented in Figure 4. Unlike the linear trend trend model,

12 The literature suggests that $\lambda$ be at 1600 for quarterly data. 
the estimated output gap is stationary.

\subsection{Multivariate Hodrick-Prescott Filter}

Adding economic structure to the model, the paper estimates the potential output using the multivariate HP filter. The relationships added to the HP filter to improve it are the Phillips curve, Okun's Law and capacity utilization. The estimation is carried out by the multivariate HP filter by minimising a weighted average of the output gap, changes in the growth rate of potential output and residual from the structural equations.

The paper first estimates the potential output and output gap using a univariate HP filter. Based on the estimated output gap a Philip's curve is estimated as:

$$
\begin{array}{cl}
\pi_{t}=0.59 \pi_{t-1}+0.346 \pi_{t-2}-0.05 \text { output gap } \\
\text { SE } & (0.1398) \quad(0.1369) \quad(0.016) \\
& R S S=0.0007
\end{array}
$$

where $\pi$ is annual inflation, the sum of squared residuals is RSS and the parenthesis contain standard errors (SE). Equation (23) clearly implies that inflation is linked to the output gap.

Following Debelle and Vickery (1997) NAIRU (Okun's law) is assumed to be a series estimated as:

$$
\begin{gathered}
U_{t}-\text { nairu }=-0.609 \text { OUTPUTGAP } \\
S E \quad(0.252) \\
R S S=0.0036
\end{gathered}
$$

Equation (24) confirms Okun's law, indicating that unemployment is negatively linked to output gap. Using data for the supply side manufacturing index, the capacity utilisation equation is estimated:

$$
\begin{gathered}
C U_{t}=6.2-10.41 \text { output gap } \\
S E \quad(0.48) \quad(4.51) \\
R S S=3.64
\end{gathered}
$$

Equation (25) also suggests that capacity utilisation is negatively linked to output gap. Using the residuals from equations (23, 24 and 25), potential output is estimated by minimizing the loss function in Equation (11). Figures 5 and 6 graphs the estimated potential output and the output gap. It has to be noted that the potential output is estimated in an iterative process until a minimum loss value based on equation (11) is obtained (Conway and Hunt (1997)).

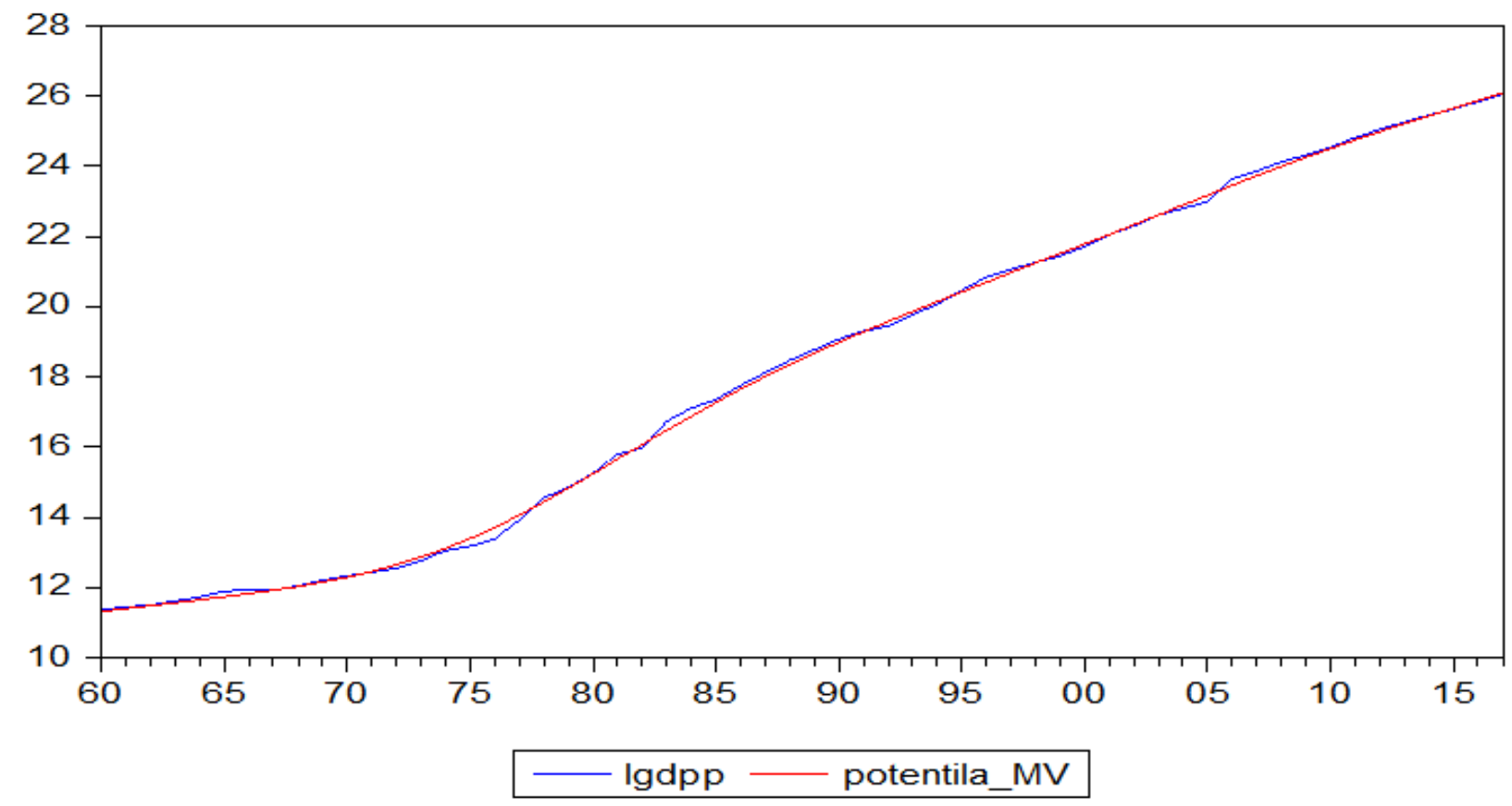

Figure 5. Actual and estimate Potential Output from the Multivariate HP Filter 


\section{MVGAP}

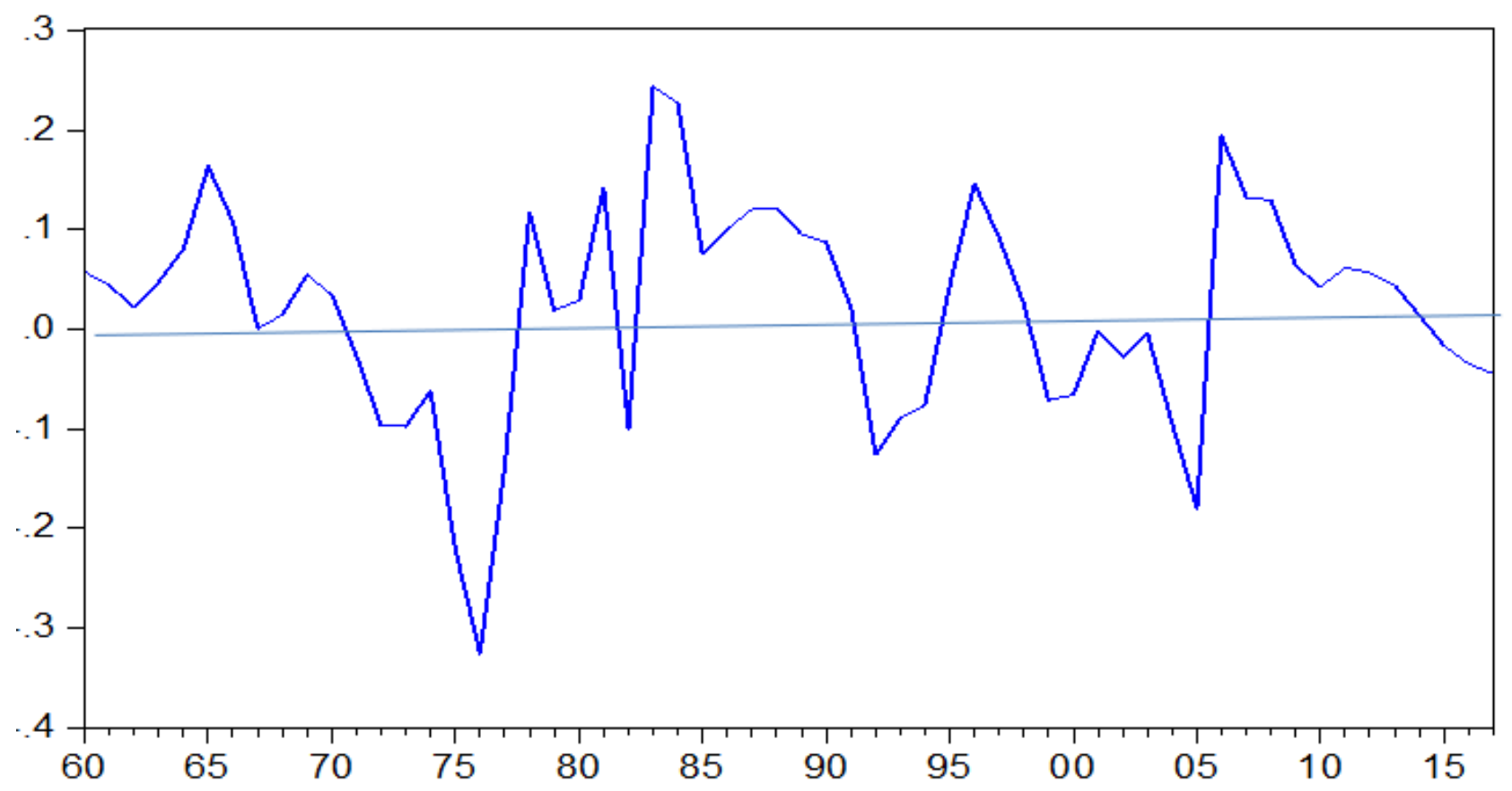

Figure 6. Output Gap derived from the Multivariate HP Filter

Figure 5 shows that the estimated potential output tracks the path of output. The corresponding output gap reveals interesting facts of Ghana's economic performance over history. What this estimation teaches us is that judgment is very critical as the accuracy and size of the estimated potential output and output gap depends on the conditioning economic information.

\subsection{Production Function}

With a view of drawing a comparison, the paper next estimates the potential output from the Cobb-Douglas production of the form:

$$
y_{t}=t f p_{t}+\propto l_{t}+(1-\propto) k_{t}
$$

where output is $\mathrm{y}$, total factor productivity is tfp, effective labour is 1 and capital stock is $\mathrm{k}$, the share of labour in income is $\alpha$. All variables are expressed in their logarithmic values. The implication of the equation (26) is that the potential output is reached when all the variables are at their equilibrium values.

Using equation (26) and following the practice in the literature, the total factor productivity is estimated by setting to 0.67 :

$$
t f p_{t}=y_{t}-0.67 l_{t}-0.33 k_{t}
$$

With the historical data on income, labour income and capital from 1960 to 2017, total factor productivity is computed. The optimum levels of the total factor productivity, capital and labour are assumed to be equivalent to their respective trends estimated using an HP filter. Potential output and consequently the output gap are computed from equation (26) based on the trend-values of the total productivity, capital and labour. Figures 8 and 9 depict the estimated potential output and output gap respectively. 


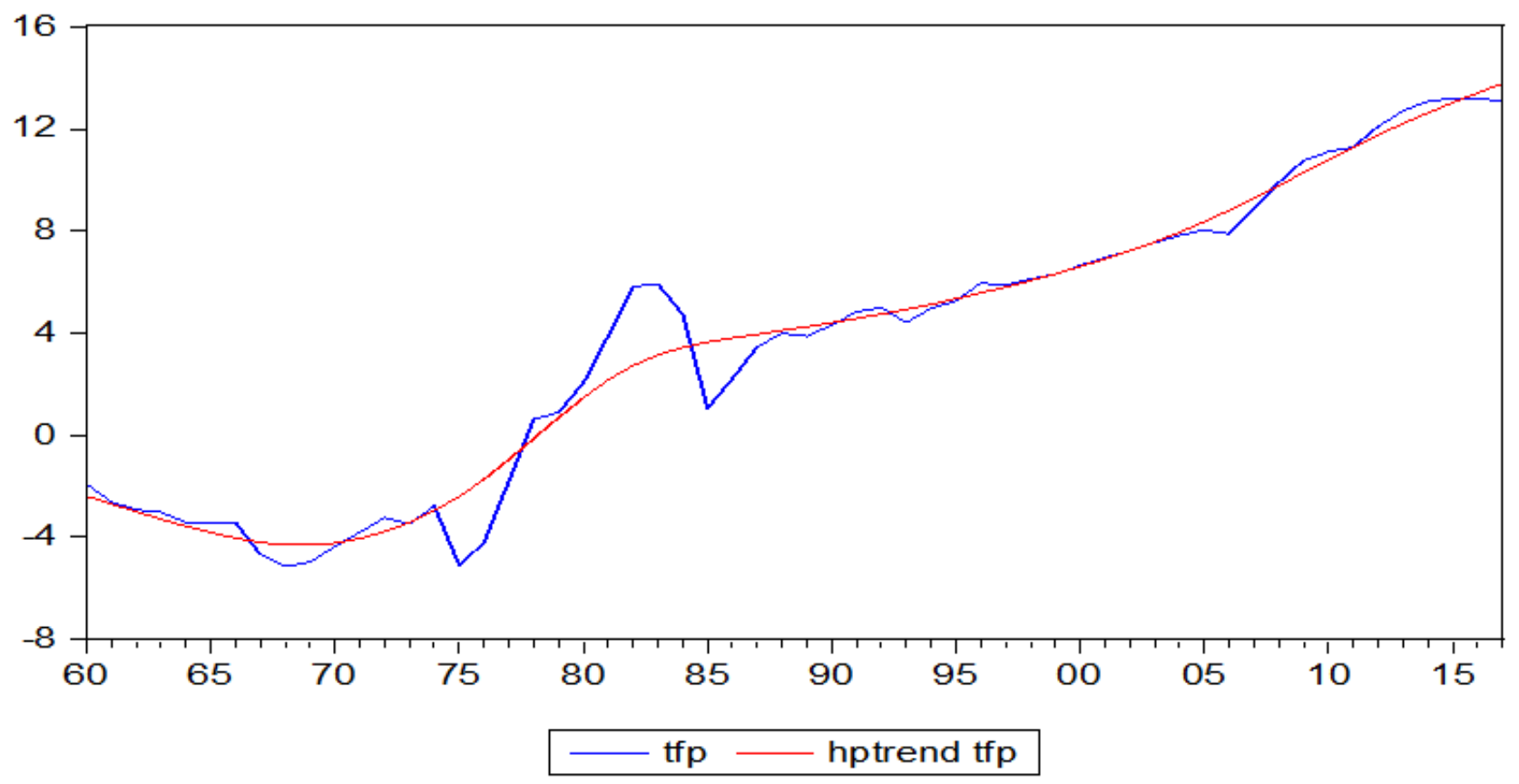

Figure 7. Total Factor Productivity and its trend from HP Filter

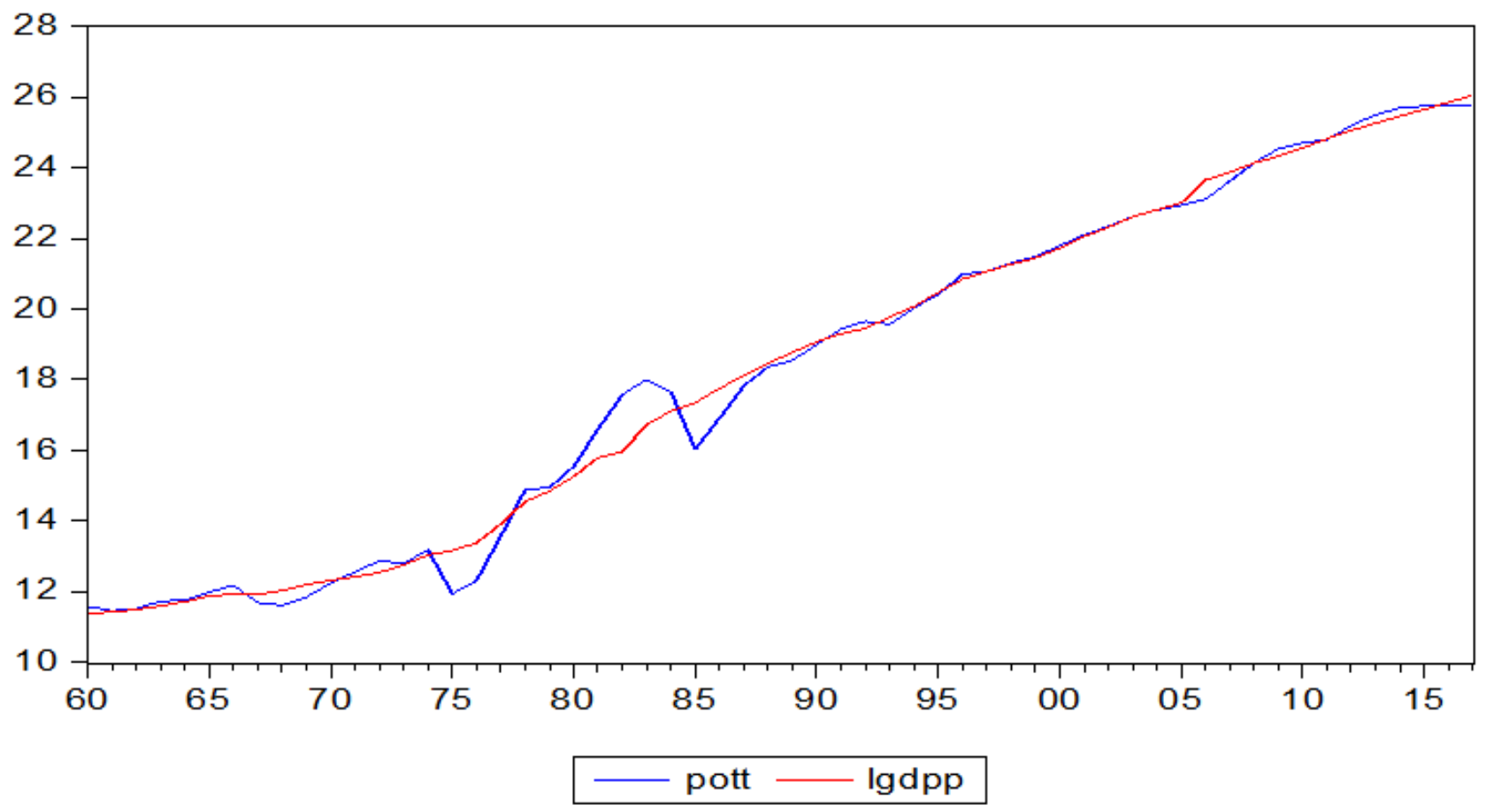

Figure 8. Actual and Estimated Potential Output by the Production Function Approach 


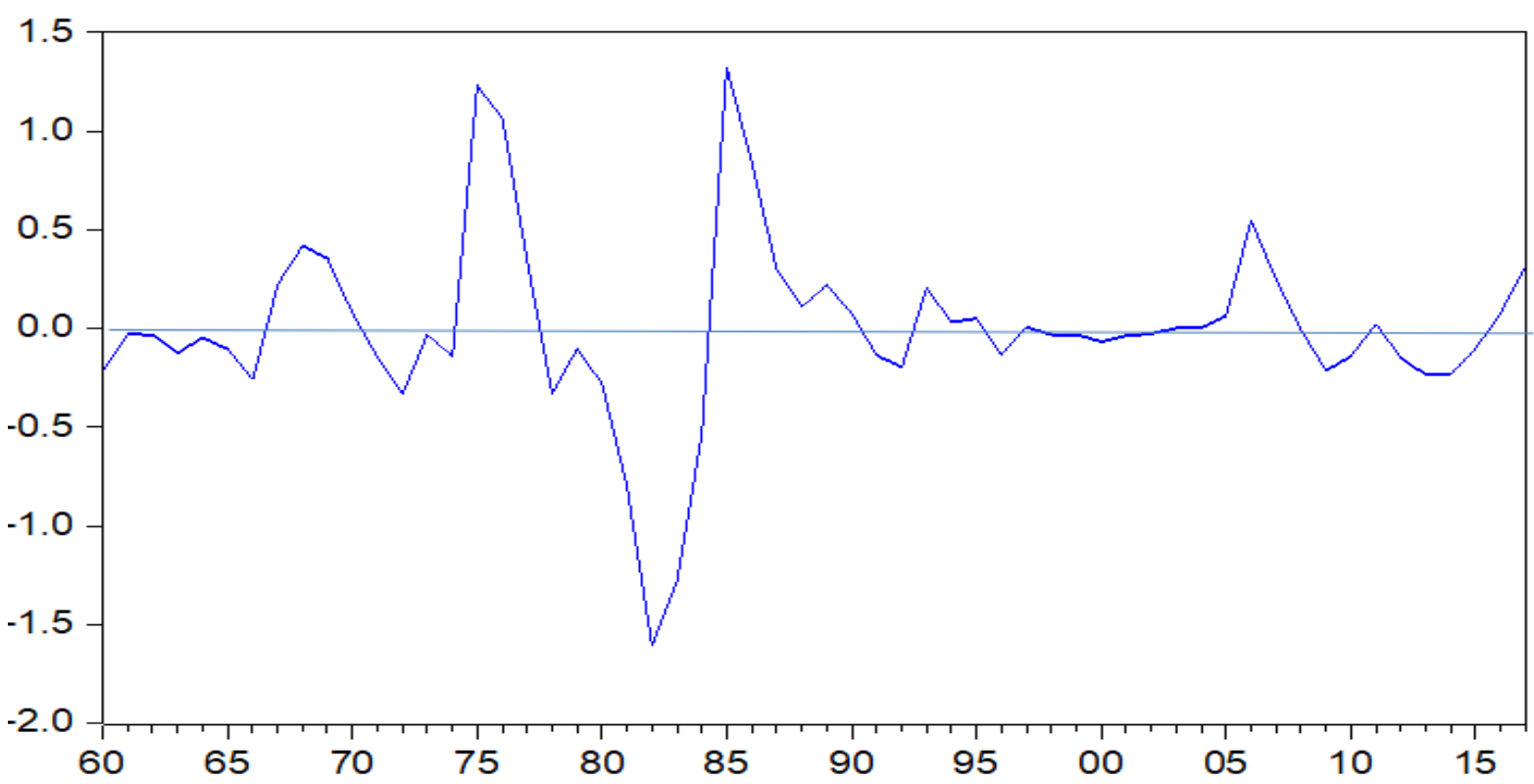

Figure 9. Output Gap by the Production Function Approach

\section{Policy Advice and Concluding Remarks}

A pertinent question to be asked at the end of reviewing various methods of estimation is which methodology is preferable? This is a very difficult question to answer. Figure 10 plot output gaps from the estimates from the 3 (univariate, multivariate and production function) out of the 4 methods discussed in Section 4. It's obvious from the graphs that size and the fluctuation of the gaps from the univariate and multivariate on one hand and that derived from the production function are different.

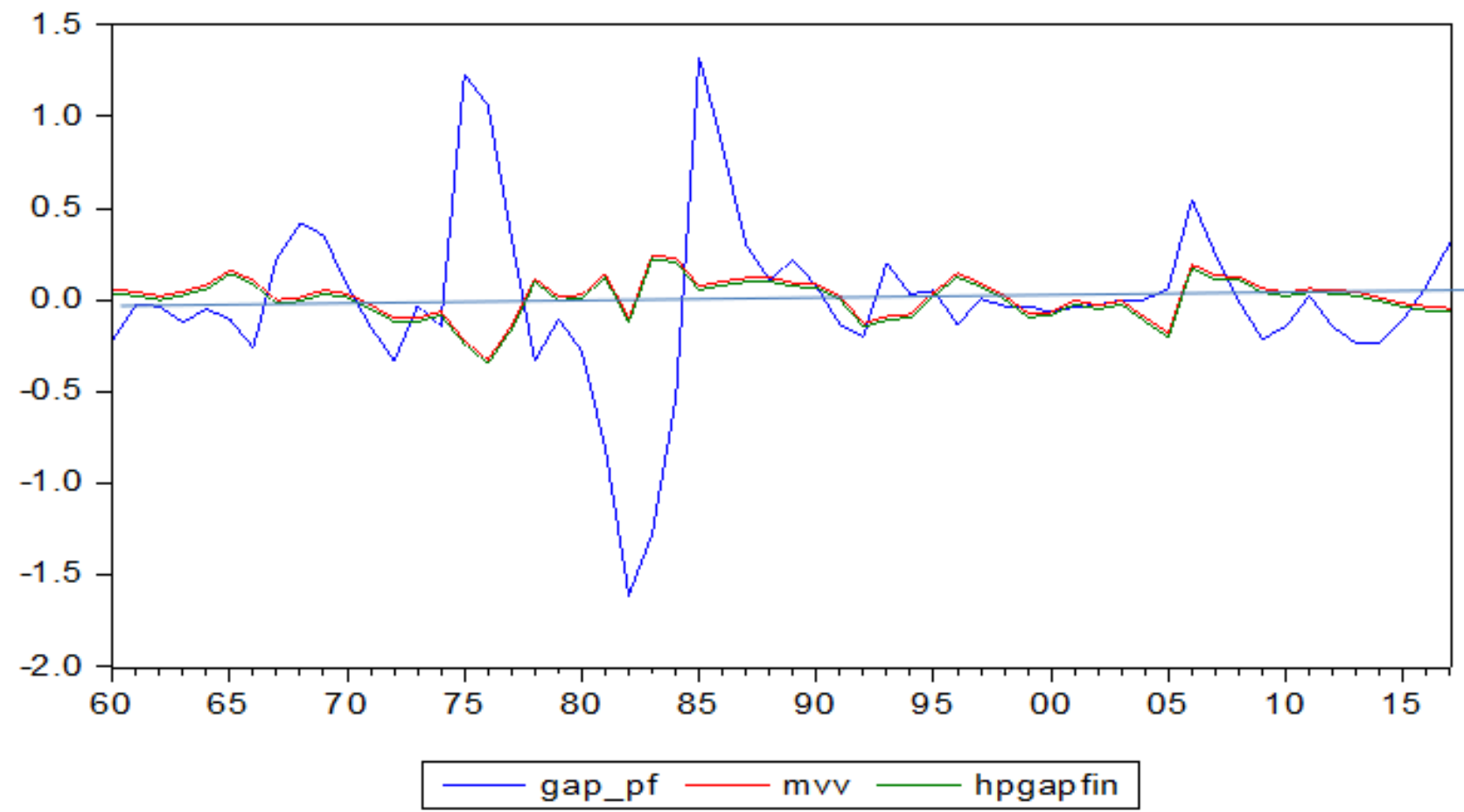

Figure 10. Estimates of Output Gap from various estimation methods Output gap estimates from univariate, multivariate and production function 
Most central banks, including that of the Bank of Ghana, take a forward-looking approach (Taylor rule) in carrying out its monetary policy. Under this framework, policymakers set the short-term nominal interest equal to the neutral rate and the weighted sum of the deviation of inflation from its target and the output gap over the forecast horizon. Hence monetary authorities that set policy interest rate based on the Taylor rule cannot afford to err on the estimation of the output gap. The consequence on the economy of using the wrong output gap in setting the policy rate is very high. As shown in Figure 10 the accuracy of the size of the output gap at a point in time is very difficult to determine. However, Figure 10 shows that the estimates from the various methodologies are broadly similar as they are reasonably correlated. Judgement requires that policymakers may have to assess current estimate of the output gap to its recent history and to past peaks and troughs.

This paper presents various methods of estimating potential output and the output gap. We have noted the strengths and weakness of each methodology. Statistically, we do not recommend the linear time trend and suggest the multivariate HP filter to be more superior than the simple HP filter. Despite the uncertainty with its estimation, the production function may provide a more accurate estimate of the potential output.

The shortcomings of the various methodologies for estimating the output gaps suggest that judgment has to be injected in the choice of models. Policymakers should not mechanistically choose a model, but should complement their model choice with judgement based on additional pertinent economic information. Given the difficulties of estimating potential output and the output gap, policymakers may consider several other indicators in order to get a better understanding of economic activities and the constraining factors. Some of the information that could guide the judgement of policy makers could include inflation relative to expectations, labour shortages, average hours worked, average hourly earnings employment, capacity utilization, and money and credit growth. Although mistakes may be made, the consequence of poor judgement in gauging the size of the output gap can be minimized when clear targets are set by the policymaker.

\section{Acknowledgement}

The authors would like to thank Mahamudu Bawumia, Ken Ofori-Atta, Atsu Amegashie, Ernest Addison, Maxwell Opoku-Afari, Philip Abradu-Otoo, Benjamin Amoah, Stephen Opata, Albert Ekow Yankey, Amma Twum-Amoah, Khadija Iddrisu, Eugene Owusu, Alhassan Iddrisu, Kwaku Appiah-Adu, Enoch Obeng-Darko Raymond Nazar and staff of Bank of Ghana who either inspired the authors to investigate the topic and/or provided insightful comments at a presentation of the draft of the paper at the Bank of Ghana. As expected the authors have benefitted immensely from the valuable technical ideas and comments of their colleagues at the UN Economic Commission for Africa. However, the views contained in this paper should not be attributed to any of the aforementioned individuals, UN and the Government of Ghana. Authors take full responsibility for omissions and errors contained in the paper.

\section{References}

Alberoa, E., Estrada, A., \& Santabarbara, D. (2013). Growth Beyond Imbalances: Sustainable Growth Rates and Output Gap Reassessment. Banco de Espana Documentos de Trabajo, 1313.

Alichi, A. (2015). A New Methodology for Estimating the Output Gap in the United States. IMF Working Paper, 15/144.

Bank of Ghana www.bog.gov.gh/statistics/time-series-data

Beveridge, S., \& Nelson, C. (1981). A new approach to decomposition of economic time series into permanent and transitory components with particular attention to measurement of the business cycle. Journal of Monetary Economics, 7, 151-174. https://doi.org/10.1016/0304-3932(81)90040-4

Blagrave, P., Garcia-Saltos, R., Laxton, D., \& Fan, Z. (2015). A simple multivariate filter for estimating potential output. IMF Working Paper ,79.

Blanchard, O., \& Quah., D. (1989). The Dynamic Effects of Aggregate Demand and Aggregate Supply. The American Economic Review, 79(4), 65573.

Borio, C., Disyatat, P., \& Juselius, M. (2013). Rethinking Potential Output: Embedding Information about the Financial Cycle. BIS Working paper No. 404.

Cockerell, L., \& Russell, B. (1995). Australian Wage and Price Inflation: 1971 - 1994. Reserve Bank of Australia Research Discussion Paper No. 9509

Conway P., \& Hunt, B. (1997). Estimating potential output: a semi-structural approach. Reserve Bank of New Zealand Discussion Paper G97/9.

de Brouwer (1998). Estimating Output Gaps. Economic Research Department Reserve Bank of Australia Research Discussion Paper No. 9809.

de Brouwer, G., \& O’Regan, J. (1997). Evaluating Simple Monetary-policy Rules for Australia, in P. Lowe (ed.), Monetary Policy and Inflation Targeting. Proceedings of a Conference, Reserve Bank of Australia, Sydney, pp. 244-276. 
de Brouwer, G., \& Ericsson, N. (1995). Modelling Inflation in Australia. Reserve Bank of Australia Research Discussion Paper No. 9510.

Debelle, G., \& Laxton, D. (1997). Is the Phillips Curve Really a Curve? Some Evidence for Canada, The United Kingdom and the United States. Staff Papers, International Monetary Fund, 44(2), 249-82. https://doi.org/10.2307/3867544

Dupasquier, C., Guay, A., \& St-Amant, P. (1997). A comparison of Alternative Methodologies for Estimating Potential Output and the Output Gap. Bank of Canada, Working Paper 97-5.

Guay, A., \& St. Amant, P. (1996). Do Mechanical Filters Provide a Good Approximation of Business Cycles? Bank of Canada Technical Report No. 78.

Harvey, A. C., \& Jaeger, A. (1993). Detrending, Stylized Facts and the Business Cycle. Journal of Applied Econometrics, 8(3), 231-247. https://doi.org/10.1002/jae.3950080302

Hodrick, R., \& Prescott, E. (1997). Post-War US Business Cycles: An Empirical Investigation. Journal of Money, Credit and Banking, 29(1), 1-16. https://doi.org/10.2307/2953682

Juselius, K. (2006). The Cointegrated VAR Model, Methodology and Applications. Oxford University Press, New York.

King, R. G., \& Rebelo, S. T. (1993). Low Frequency Filtering and Real Business Cycles. Journal of Economic Dynamics and Control, 17(1-2), 207-231 https://doi.org/10.1016/S0165-1889(06)80010-2

Laxton, D., \& Tetlow, R. (1992). A Simple Multivariate Filter for the Measurement of Potential Output. Bank of Canada Technical Report No. 59

Lippi, M., \& Reichlin, L. (1994). VAR analysis, non-fundamental representations, Blaschke matrices. Journal of Econometrics, 63(1), 307-325. https://doi.org/10.1016/0304-4076(93)01570-C

Okun, A. M. (1962). Potential GNP: Its Measurement and Significance, in Proceedings of the Business and Economic Statistics Section, pp. 98-104 Washington: American Statistical Association

Phillips, A. (1958). The Relationship between Unemployment and the Rate of Change of Money Wage Rates in the United Kingdom, 1861-1957. Economica, 25(100), 283-299.

Shapiro, M. D., \& Watson, M. W. (1988). Sources of Business Cycle Fluctuations. Working Paper 2589. National Bureau of Economic Research, Cambridge (MA). https://doi.org/10.3386/w2589

St Amant, P., \& van Norden, S. (1997). Measurement of the Output Gap: A Discussion of Recent Research at the Bank of Canada. Bank of Canada Technical Paper.

Watson, M. W. (1986). Univariate Detrending Methods with Stochastic Trends. Journal of Monetary Economics, 18(1), 49-75. https://doi.org/10.1016/0304-3932(86)90054-1

\section{Copyrights}

Copyright for this article is retained by the author(s), with first publication rights granted to the journal.

This is an open-access article distributed under the terms and conditions of the Creative Commons Attribution license which permits unrestricted use, distribution, and reproduction in any medium, provided the original work is properly cited. 